\title{
Longitudinal assessment of depression, stress, and burnout in medical students
}

\author{
Akhil D. Goel, Sulbha V. Akarte', Sumita P. Agrawal², Vikas Yadav \\ Centre for Community Medicine, All India Institute of Medical Sciences, '²epartment of Pulmonary, Critical Care and Sleep Medicine, \\ Vardhaman Mahavir Medical College and Safdarjung Hospital, New Delhi, ${ }^{1}$ Department of Community Medicine, Grant Medical College, \\ Mumbai, Maharashtra, India
}

\begin{abstract}
Background: Medical students can and do suffer from mental disorders is a concept yet to get wide acceptance. There are few studies comprehensively evaluating depression, stress, and burnout in medical students, especially in a longitudinal way in India. The current study aims to assess the impact of medical education on the development of psychological morbidities and the role of personality. Materials and Methods: First-year medical students of a leading medical college of India were enrolled on admission and given anonymized, validated, self-administered questionnaires assessing depression, stress, burnout, and personality. This was repeated at the end of $1^{\text {st }}$ year. Data were analyzed independently as questionnaires were anonymized. Results: We found that $1^{\text {st }}$ year of medical college showed a significantly increasing depression $(P<0.01)$ and stress $(P<0.01)$. Overall burnout did not increase significantly. However, only disengagement dimension of burnout increased significantly. Personalities with weak capacity to adjust had a significant positive correlation with depression $(r=0.277, P<0.001)$ and stress scores $(r=0.210, P=0.008)$. However, burnout did not correlate with any of the personality dimensions. Conclusion: Right from the $1^{\text {st }}$ year of medical education students perceive high-stress levels and have a high risk of depression. Burnout starts to creep in at least in the form of disengagement. This study provides a sound groundwork for planning interventions to reduce student's mental morbidity and avoid burnout.
\end{abstract}

Keywords: Burnout, depression, medical students, stress

\section{Introduction}

There are 52,715 Bachelor of Medicine and Bachelor of Surgery (MBBS) seats across 412 medical colleges in India. ${ }^{[1]}$ And, more than 10 times are the numbers of applicants eyeing for entry to this coveted field. There is usually a selection bias such that those who are intelligent have high levels of personal drive and demands from self usually enter medical schools. Most are multitalented and scientifically curious. Many are perfectionists and may get restless with underperformance and even impatient with underperformers. All these behavioral

\section{Address for correspondence:}

Dr. Akhil D. Goel, Centre for Community Medicine, All India Institute of Medical Sciences, Old OT Block, New Delhi - 110 029, India.

E-mail: doc.akhilgoel@gmail.com

\begin{tabular}{|l|l|}
\hline \multicolumn{2}{|c|}{ Access this article online } \\
\hline Quick Response Code: & Website: \\
\hline & www.ruralneuropractice.com \\
\cline { 2 - 3 } & \\
\hline
\end{tabular}

characteristics and many more factors interact with the learning environment and individual expectation to finally pave a way for current performance levels and future career choices. ${ }^{[2]}$

The High-Level Expert Group report has recommended a steep increase in medical colleges and medical seats in India. ${ }^{[3]}$ While the Medical Council of India ensures staff adequacy and recommends academic medical curriculum, there is little focus on mental health problems of medical undergraduates, postgraduates, or teachers. ${ }^{[1]}$

The current medical education system has become a rat-race due to cut-throat competition and peer pressure

This is an open access article distributed under the terms of the Creative Commons Attribution-NonCommercial-ShareAlike 3.0 License, which allows others to remix, tweak, and build upon the work non-commercially, as long as the author is credited and the new creations are licensed under the identical terms.

For reprints contact: reprints@medknow.com

How to cite this article: Goel AD, Akarte SV, Agrawal SP, Yadav V. Longitudinal assessment of depression, stress, and burnout in medical students. J Neurosci Rural Pract 2016;7:493-8. 
threatening mental health of medical students. Doctors and health care workers are exposed to the occupational hazards manifesting as psychiatric and psychological symptoms. ${ }^{[4,5]}$ That medical students can and do suffer from "occupational" mental disorders is a concept yet to get wide acceptance.

Burnout is a relatively modern concept which was first used by Freudenberger in 1974 to describe a state of exhaustion (most often emotional and mental) different from depression observed among volunteer workers. ${ }^{[6]}$ Demerouti et al. have developed and validated the Oldenburg Burnout Inventory (OLBI) which measures burnout across two dimensions - exhaustion and disengagement. ${ }^{[7]}$

There are few Asian studies comprehensively evaluating depression, stress and burnout in medical students, especially in a longitudinal way in India. Furthermore, there is a lack of evidence of personality interacting with medical education to predispose psychological morbidities in medical students. The current study was undertaken to study these in detail.

\section{Materials and Methods}

This was a longitudinal study conducted at a premiere Medical College of India. A self-administered semi-structured anonymized questionnaire was given to all the $1^{\text {st }}$ year medical students $(n=197$, universal sampling) at the beginning of their $1^{\text {st }}$ year MBBS to assess for depression using Major Depression Inventory stress using Cohen's Perceived Stress Scale-10 and burnout using OLBI. ${ }^{[7-11]}$ Although these scales are originally from Western countries, they have been widely used across various other countries including India. ${ }^{[12,13]}$ Furthermore, there is a dearth of widely used indigenous psychometric scales tailor-made for Indian population. ${ }^{[14]}$ A period of 1 year was allowed to pass where the students underwent their usual curriculum and exams. Thereafter, the same questionnaire with same tools was repeated after 1 year to assess the change over the $1^{\text {st }}$ year of medical education. A risk profile questionnaire was concomitantly used which included measurement of sociodemographic profile and personality using the big five personality scale. This scale measured personality across five dimensions, namely, openness (inventive/curious vs. consistent/cautious), conscientiousness (efficient/ organized vs. easy-going/careless), sociability (outgoing/ energetic vs. solitary/reserved), agreeableness (friendly/ compassionate vs. cold/unkind), and Adjustment (sensitive/nervous vs. secure/confident). ${ }^{[15]}$ This is a checklist of 25 attributes each of which is be marked on a visual analog scale of 1-5. A composite score is then calculated against each of the five personality attributes.

It was explained to all students that the completion of the questionnaires was voluntary, that the answers were confidential, that anonymity would be assured and that the results would be used for student welfare policies and better academic planning. Institutional Ethical Committee approval was obtained before the start of the study. Statistical analysis was done using SPSS Version 17.0 (SPSS Inc. Released 2008. SPSS Statistics for Windows, Version 17.0. Chicago: SPSS Inc.). Proportions were compared using Chi-square test or Fischer exact test. Mean scores were compared using independent $t$-tests. The Shapiro-Wilk test gave $P<0.05$ for all the personality norm scores indicating that these are not normally distributed. Hence, correlations of personality scores were calculated using Spearman's rho test.

\section{Results}

At the start of medical education, 160 students (out of 197) returned completely filled questionnaires giving a response rate of $81.2 \%$. At follow-up after 1 year, 134 completed questionnaires were received giving the response rate of $68 \%$. The age, gender, and socioeconomic status distribution were similar at both baseline and follow-up.

Preexisting depression was reported by $8.75 \%$ students at baseline. This proportion increased to $22.58 \%$ indicating an almost 3-fold increase in depression tendencies developing over $1^{\text {st }}$ year of medical college $(P<0.001)$. The depression score increased from a mean 9.19 at baseline to 12.69 at follow-up $(P<0.01)$ [Figure 1]. Similarly, stress scores also increased significantly $(P<0.01)$ [Figure 2]. The exhaustion dimension of burnout did not show significant

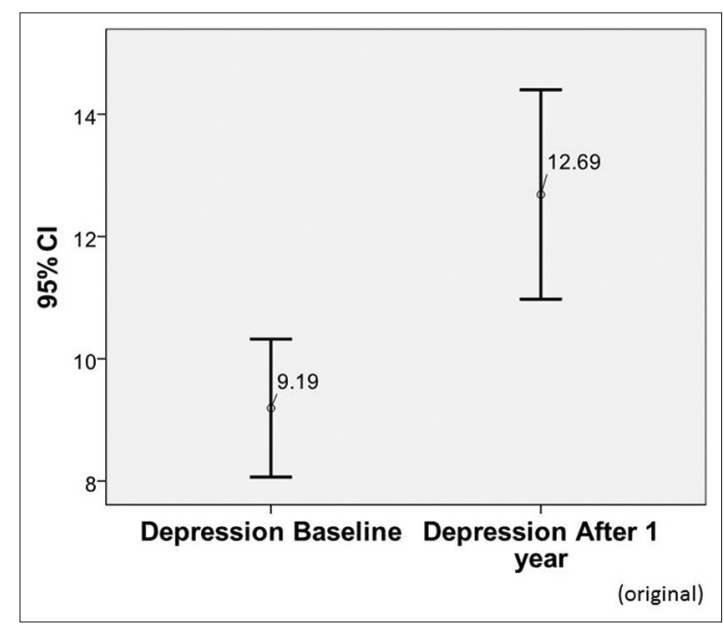

Figure 1: Depression using WHO Major Depression Inventory Scores 
change $(P=0.26)$ [Figure3] but the disengagement dimension did witness a significant increase $(P<0.01)$ [Figure 4 ].

Personality across five dimensions was investigated as a risk factor for psychological outcomes. Almost 50\%

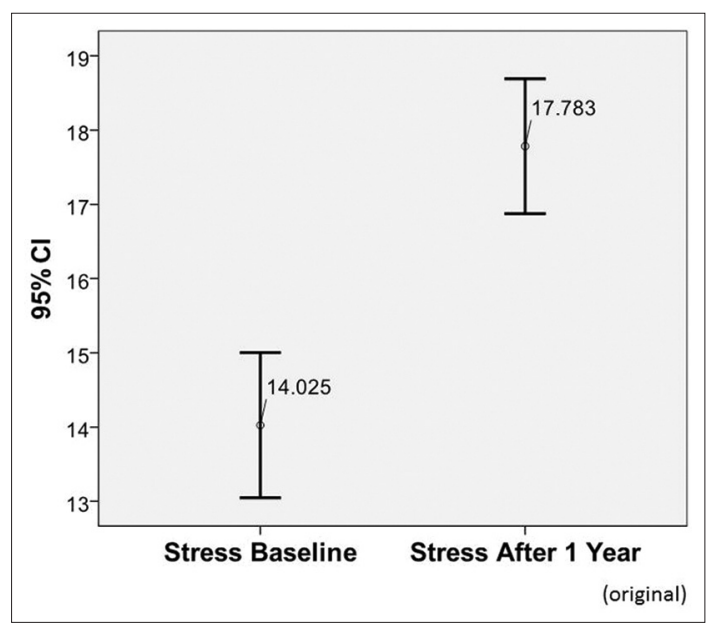

Figure 2: Stress using Perceived Stress Scale-10 scores

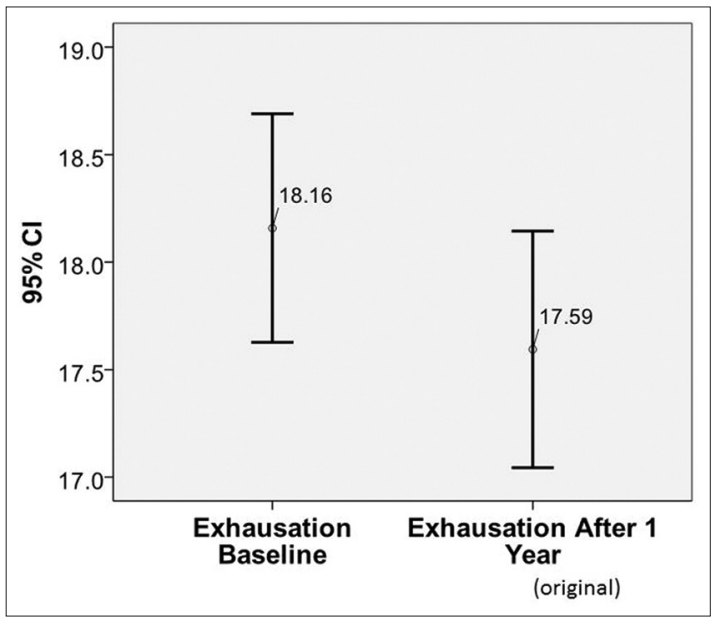

Figure 3: Burnout - exhaustion dimension

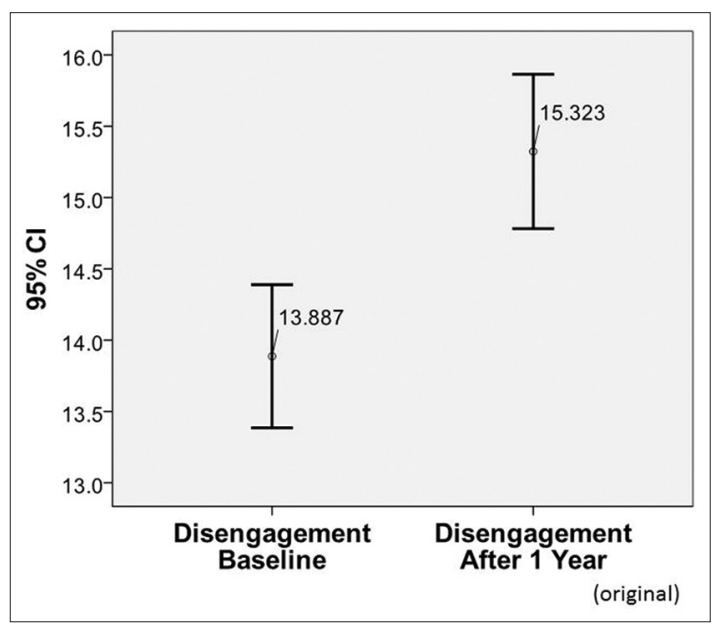

Figure 4: Burnout - disengagement dimension students were low adjusters and scored low in openness. Personalities with weak capacity to adjust had a significant positive correlation with depression $(r=0.277, P<0.001)$ and stress scores $(r=0.210, P=0.008)$. Higher depression scores were seen in those high openness $(P=0.002)$ and high agreeableness $(P=0.047)$. Burnout did not correlate with any of the personality dimensions.

Those with physical medical problems $(n=58)$ reported higher stress $(P=0.003)$ and higher disengagement dimension of burnout than others $(P=0.016)$. Twelve students $(7.5 \%)$ admitted of pursuing MBBS on parents' insistence against their own interests. These showed higher depression scores $(P=0.015)$.

Various other risk factors studied were gender, hostel dwelling, socioeconomic status, education status of parents, number of attempts at premedical entrance exams, type of exam (i.e., All India Entrance or State Entrance Exams), rural residence, first language in junior college other than English, presence of a doctor in family or close relation. However, none of these were found to be significantly associated with psychological outcomes.

\section{Discussion}

Inthisstudy, depressionscoresofmedicalstudentsincreased significantly at 1 year follow-up [Table 1 and Figure 1]. However, the number of students who reported depression did not change significantly. This implies that students who have a milder tendency for the depressed mood at baseline are likely to suffer an exaggeration at follow-up. This finding is in accordance with Guthrie et al. who, in a 5 years prospective study, evaluated $1^{\text {st }}$ year medical students and concluded that those students who were depressed in the beginning were likely to remain so during the training. ${ }^{[16]}$ Personality traits such as weak adjustment, high openness, and high agreeableness reported higher depression. In addition, those joining MBBS due parental pressure tended to have higher depression scores.

One year of medical education has significantly increased stress in medical students [Table 1 and Figure 2].

\begin{tabular}{|c|c|c|c|c|}
\hline Psychological outcomes & $\begin{array}{c}\text { Baseline } \\
(n=160)\end{array}$ & $\begin{array}{c}\text { Follow-up } \\
(n=134)\end{array}$ & $P$ & $t$ \\
\hline Depression, mean $\pm S D$ & $9.26 \pm 6.34$ & $12.69 \pm 9.64$ & $<0.01$ & -3.6 \\
\hline Stress, mean $\pm S D$ & $14.55 \pm 8.68$ & $17.78 \pm 5.03$ & $<0.01$ & -3.7 \\
\hline \multicolumn{5}{|l|}{ Burnout (mean $\pm S D$ ) } \\
\hline Exhaustion & $18.02 \pm 3.12$ & $17.59 \pm 3.21$ & 0.26 & 1.4 \\
\hline Disengagement & $14.02 \pm 2.95$ & $15.38 \pm 2.78$ & $<0.01$ & -3.4 \\
\hline
\end{tabular}


Specifically, weak adjusters $(P=0.008)$ and those with physical medical problems $(P=0.003)$ were more associated with stress. This is in sync with many studies which state that there are also many other stressors in medical education like difficulty in adjusting to the new environment, first encounters with human cadaveric dissections, increased scholastic workload, competitive pressure for best academic performance, voluminous information load, change in the language of instruction, ragging, and ill-treatment by seniors and racial discrimination..$^{[4,17]}$

The medical students in this study did not show a significant difference in the exhaustion dimension of burnout [Table 1 and Figure 3]. This indicates that the $1^{\text {st }}$ year medical students did not easily tire before going to their classes/practicals or after finishing studies. Also, this suggests that their job demands are not so high that they cannot recover in their off-time. Many studies on physician burnout indicate that interns, residents, and practicing physicians are already tired before going to their work, that they are not able to recover even after their job is over and that their burnout is associated with higher medical errors. ${ }^{[18]}$ This may be due to the excessive physical demands (e.g., long working hours, irregular breaks, etc.,) and emotional demands (e.g., dealing with patient mortality, relative's grief, interpersonal conflicts, etc.). That $1^{\text {st }}$ year students in this study did not get exhausted indicates that they are still vigorous and motivated in learning and are not yet tired of it.

The disengagement dimension of burnout was, however, significantly increased in the follow-up as compared to baseline [Table 1 and Figure 4]. Disengagement is an indicator of inadequate "job resources." In the case of the $1^{\text {st }}$ year medical students, higher disengagement would translate into suboptimal learning conditions, lower task variety, inadequate feedback, and support from seniors and also inability in making decisions. Also, this may indicate that the students feel a kind of disillusionment toward their studies in general and that they do not find interesting aspects in their routine work, and thus, they stop feeling engaged in what they do. In the further years of MBBS, as the course becomes more demanding and students are exposed to patients (increased job demands); and the learning system not improving much (decreased job resources), the chances of unmasking of the exhaustion and increase in the disengagement is likely. ${ }^{[19,20]}$

Gender and hostel dwelling were not associated with psychological outcomes. This is in contrast with the perception that females and hostel dwellers are more prone to stress and psychological problems. ${ }^{[21,22]}$
However, the duration of the current study is just the initial 1 year. Thus, the higher cumulative duration of staying in hostel in the subsequent years of medical education may unfurl the higher vulnerability of hostel dwellers for psychological problems.

There were 12 students (7.5\%) who clearly indicated that they did not seek admission into MBBS themselves but were doing so on their parent's insistence. These students showed a significantly higher depression as compared to others. Lack of decision-making power and forced career choices can lead to clinical depression and even suicidal tendencies in these students. They needed to be identified early and counseled along with the entire family.

The presence of a doctor in the family was not shown to be protective or predictive of psychological problems in medical students. A person who knows the nuances of the medical education will be able to guide the students and prepare him/her for the stressful journey. This, however, was not observed in this study. However, in the later years of the medical education and career planning, this might be an important factor to prevent or decrease the psychological stress and the accompanying psychiatric morbidities.

Personality refers to the patterns of thoughts, feelings, and behaviors consistently exhibited by an individual over time that strongly influence our expectations, self-perceptions, values and attitudes, and predicts our reactions to people, problems, and stress. ${ }^{[17]}$ In this study, personalities with weak capacity to adjust had a significant positive correlation with depression $(r=0.277$, $P<0.001)$ and stress scores $(r=0.210, P=0.008)$. We can thus conclude that those students with weaker adjustment personality are more prone to develop psychological problems. This can have important policy implications in that students with weaker adjustment dimension can and should be identified earlier and provided with additional system support to prevent stress and depression. Depression is also seen to be associated with openness $(r=0.241, P=0.002)$ and agreeableness scores $(r=0.157, P=0.047)$. Thus, students who are less adjusting, more open, and more agreeable also are likely to develop depression. Burnout did not correlate with any of the personality dimensions. This reconfirms the concept that burnout arises due to extrinsic job-related factors, namely, high job demands, and lowered job resources and not due to intrinsic student personality characteristics.

Medical students can be considered as a subset of population who are highly motivated, action-oriented achievers, securing high grades before admission to 
the medical school. Many are perfectionists and may get restless with underperformance and impatient with delayed achievement. They often cannot tolerate feelings of helplessness, dependency and are therefore more prone to stress or incapable of handling it. They also seem to have harsh self-criticism, self-doubt, a feeling of inferiority but high aspirations and rigid standards for themselves. ${ }^{[23]}$ Medical students have to deal with many specific stressors such as information and input overload, financial dependency and indebtedness, work stress, work relationships, lack of leisure time, and career uncertainties. Many students are for the first time leaving their homes and thus are exposed to a new environment lacking the accustomed familial support. The first time rendezvous with human suffering, death, sexuality issues can be far more intimidating and stressful. The harrowing expanse of premedical entrance studies along with societal expectations and emotional peer pressure push students to the edge of their abilities. All this may cause mental health problems; medical students can thus be considered as a high-risk group for psychological morbidities. After accidents, suicides are the most common cause of death in medical students. ${ }^{[5]}$

The response rate of students was $92.9 \%$ at baseline and $68 \%$ at 1 year follow-up. These are comparable to other similar studies on medical students. ${ }^{[24-26]}$ However, the fact remains that nonresponders might typically have more than expected burden of stress and psychological morbidity, thereby affecting the precision of the study. ${ }^{[27]}$ Or the distressed students may be less motivated to fill the questionnaire; or that they would be more likely to participate because the topic is relevant to them. All these could lead to a nonresponse bias. Also, it was assumed that since the medium of instruction is English; all students must know English language, and therefore all questionnaires were in English language only. However, there were 56 students having their first language other than English at their $10^{\text {th }}$ grade and 7 such students at the $12^{\text {th }}$ grade. These students might have found it difficult to understand the psychometric questionnaires thereby leading a measurement bias.

\section{Conclusion}

This follow-up study done at a leading Government Medical College of India has highlighted many important facts about the mental health of medical students. Right from the $1^{\text {st }}$ year of medical education students perceive high-stress levels and have a high risk of depression. Burnout starts to creep at least in the form of disengagement. However, numbers cannot possibly depict the exact picture of what a student experiences.
Nonetheless, whatever small amount of data analyzed in this study and available in literature roars the need for medical education planners to put on their thinking caps and plan for interventions to reduce student's mental morbidity and avoid burnout. Medical colleges should consider having regular screening of medical students for timely identification of psychological disorders, especially arising due to the education process. Those with high risk-personalities like low adjusters could be identified right from the inception of medical education and given focused evidence-based interventions like counseling to avoid psychological problems. We, as a system, need to realize that medical school is potentially an organization and look into student's mental health and accordingly promote a psychologically sound learning and practicing environment. The psychological well-being of medical students needs to be more carefully addressed, and closer attention needs to be paid to the styles of medical teaching that may provoke avoidable distress.

\section{Financial support and sponsorship Nil.}

\section{Conflicts of interest}

There are no conflicts of interest.

\section{References}

1. MCI. Medical Council of India: List of Colleges Teaching MBBS; 2010. Available from: http://www.mciindia.org/InformationDesk/ ForStudents/ListofColleges'TeachingMBBS.aspx. [Last cited on 2016 Mar 01].

2. Wilhelm KA. The student and junior doctor in distress. Med J Aust 2002;177 Suppl 1:S5-8.

3. Planning Commission of India. High Level Expert Group Report on Universal Health Coverage for India. New Delhi: Planning Commission of India; 2011. Available from: http://www.planningcommission.nic.in/ reports/genrep/rep_uhc0812.pdf. [Last cited on 2016 Apr 01].

4. Goldhagen BE, Kingsolver K, Stinnett SS, Rosdahl JA. Stress and burnout in residents: Impact of mindfulness-based resilience training. Adv Med Educ Pract 2015;6:525-32.

5. Andrew LB, Brenner BE. Physician Suicide: WebMD LLC.; 2016. Available from: http://www.emedicine.medscape.com/article/8067 79-overview\#showall. [Last updated on 2016 Jun 01; Last cited on 2016 Apr 01].

6. Freudenberger HJ. Staff burn-out. J Soc Issues 1974;30:159-65.

7. Demerouti E, Bakker AB, Vardakou I, Kantas A. The convergent validity of two burnout instruments. Eur J Psychol Assess 2003;19:12-23.

8. Bech P, Rasmussen NA, Olsen LR, Noerholm V, Abildgaard W. The sensitivity and specificity of the Major Depression Inventory, using the Present State Examination as the index of diagnostic validity. J Affect Disord 2001;66:159-64.

9. Olsen LR, Jensen DV, Noerholm V, Martiny K, Bech P. The internal and external validity of the Major Depression Inventory in measuring severity of depressive states. Psychol Med 2003;33:351-6.

10. Cohen S, Kamarck T, Mermelstein R. A global measure of perceived stress. J Health Soc Behav 1983;24:385-96.

11. Leiter MP, Schaufeli WB. Consistency of the burnout construct across occupations. Anxiety Stress Coping 1996;9:229-43.

12. Goel D, Trivedi JK. Clinical practice guidelines for psychiatrists: Indian Psychiatric Society guidelines vs. international guidelines: A critical 
appraisal. Indian J Psychiatry 2007;49:283-6.

13. Grover S, Dutt A, Avasthi A. An overview of Indian research in depression. Indian J Psychiatry 2010;52 Suppl 1:S178-88.

14. Venkatesan S. Indian scales and inventories. Indian J Psychiatry 2010;52 Suppl 1:S378-85.

15. John OP, Naumann LP, Soto CJ. Paradigm shift to the integrative big five trait taxonomy: History, measurement, and conceptual issues. In: John OP, Robins RW, Pervin LA, editors. Handbook of Personality: Theory and Research. $3^{\text {rd }}$ ed. New York: The Guilford Press; 2008. p. 114-58.

16. Guthrie EA, Black D, Shaw CM, Hamilton J, Creed FH, Tomenson B. Psychological stress in medical students: A comparison of two very different university courses. Stress Med 1997;13:179-84.

17. Thomas JC, Segal DL. Comprehensive Handbook of Personality and Psychopathology, Personality and Everyday Functioning. Hoboken, N.J.: Wiley; 2005. p. 496.

18. West CP, Huschka MM, Novotny PJ, Sloan JA, Kolars JC, Habermann TM, et al. Association of perceived medical errors with resident distress and empathy: A prospective longitudinal study. JAMA 2006;296:1071-8.

19. Demerouti E, Bakker AB, Nachreiner F, Schaufeli WB. The job demands-resources model of burnout. J Appl Psychol 2001;86:499-512.

20. Demerouti E, Bakker AB, de Jonge J, Janssen PP, Schaufeli WB. Burnout and engagement at work as a function of demands and control. Scand J Work Environ Health 2001;27:279-86.

21. Nolen-Hoeksema S. Gender differences in depression. Curr Dir Psychol Sci 2001;10:173-6.

22. Devi K, Patel R, Ashok. Study of psychological depression and its associated factors among medical students in Pondicherry. Indian J Basic Appl Med Res 2013;2:1009-16.

23. Rodolfa E, Chavoor S, Velasquez J. Counseling services at the University of California, Davis: Helping medical students cope. JAMA 1995;274:1396-7.

24. Demerouti E, Bakker AB, Nachreiner F, Schaufeli WB. A model of burnout and life satisfaction amongst nurses. J Adv Nurs 2000;32:454-64.

25. Sreeramareddy CT, Shankar PR, Binu VS, Mukhopadhyay C, Ray B, Menezes RG. Psychological morbidity, sources of stress and coping strategies among undergraduate medical students of Nepal. BMC Med Educ 2007;7:26.

26. Dyrbye LN, Thomas MR, Massie FS, Power DV, Eacker A, Harper W, et al. Burnout and suicidal ideation among U.S. medical students. Ann Intern Med 2008;149:334-41.

27. Vernon SW, Roberts RE, Lee ES. Ethnic status and participation in longitudinal health surveys. Am J Epidemiol 1984;119:99-113.

\section{Staying in touch with the journal}

1) Table of Contents (TOC) email alert Receive an email alert containing the TOC when a new complete issue of the journal is made available online. To register for TOC alerts go to www.ruralneuropractice.com/signup.asp.

\section{2) RSS feeds}

Really Simple Syndication (RSS) helps you to get alerts on new publication right on your desktop without going to the journal's website. You need a software (e.g. RSSReader, Feed Demon, FeedReader, My Yahoo!, NewsGator and NewzCrawler) to get advantage of this tool. RSS feeds can also be read through FireFox or Microsoft Outlook 2007. Once any of these small (and mostly free) software is installed, add www.ruralneuropractice.com/rssfeed.asp as one of the feeds. 